September 10, 2012

Dr. Paul Demkowicz

Idaho National Laboratory

P.O. Box 1625, 2525 North Freemont Avenue

Idaho Falls, Idaho 83415

SUBJECT: Completion of Level 2 Milestone Activity - Complete Safety Test Report for ORNL Completed Safety Tests

Paul,

This letter formally documents successful completion of the Next Generation Nuclear Plant (NGNP) Level 2 Milestone (M2GR-12IN05010410), "Complete safety test report for ORNL completed safety tests," due September 15, 2012. Work was performed under Memorandum Purchase Order MPO-83494, Statement of Work SOW-6904, Revision 4.

Safety tests were performed in the Core Conduction Cooldown Test Facility (CCCTF) at ORNL. Three Baseline fuel compacts from the AGR-1 irradiation experiment were individually subjected to $1600^{\circ} \mathrm{C}$ in flowing helium gas for a minimum of 300 hours. Release of $\mathrm{Kr}-85$ was monitored for indication of complete particle coating failure, and none was observed. Release of Cs-137 was monitored for indication of $\mathrm{SiC}$ coating failure. One particle in Compact 3-3-2 released cesium through a defective $\mathrm{SiC}$ layer; no other particles with $\mathrm{SiC}$ defects were detected. After deconsolidating Compact 3-3-2, the one defective particle was identified and sorted out using the Irradiated Microsphere Gamma Analyzer (IMGA) and determined by x-ray tomography to be one of the expected SiC soot inclusion defects, which had been previously identified to be present in the pre-irradiated fuel. Other condensable fission products that escaped from the compacts were also collected throughout the experiment. As expected, silver and europium were the dominant release products through intact coating layers. Details of the CCCTF safety tests and post-safety test analyses will be documented in individual AGR-1 compact postirradiation examination (PIE) reports. The attached safety test report summarizes the results of the three safety tests, including initial fission product release results.

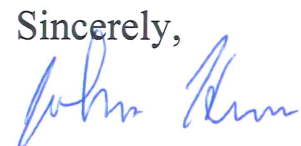

John D. Hunn

Distinguished Research Staff

Oak Ridge National Laboratory

Attachment: ORNL/LTR-2012/396, Safety Tests on Irradiated AGR-1 Compacts 3-3-2, 3-2-2, and $6-2-1$ 
ORNL/LTR-2012/396

\section{SAFETY TESTS ON IRRADIATED AGR-1 COMPACTS 3-3-2, 3-2-2, AND 6-2-1}

\section{Summary}

Post-irradiation examination (PIE) is in progress on coated particle fuel compacts from the first Advanced Gas Reactor irradiation experiment (AGR-1). The AGR-1 Post-Irradiation Examination Plan, INL/PLN2828/Rev. 1, includes safety testing of the irradiated compacts in the Oak Ridge National Laboratory (ORNL) Core Conduction Cooldown Test Facility (CCCTF) facility and the Idaho National Laboratory Fuel Accident Condition Simulator (FACS) to evaluate the effect of elevated temperature on the fuel microstructure and fission product retention. Safety tests will involve heating compacts for 100500 hours to maximum temperatures of $1600^{\circ} \mathrm{C}-1800^{\circ} \mathrm{C}$, where $1600^{\circ} \mathrm{C}$ is the expected maximum temperature during a high-temperature gas-cooled reactor depressurization conduction cooldown event, and $1800^{\circ} \mathrm{C}$ is the expected temperature at which the performance of the $\mathrm{SiC}$ layer will begin to degrade.

ORNL completed the first AGR-1 post-irradiation compact safety test in FY2011. During the first two quarters of FY2012, three additional safety tests were completed. Each of these three compacts was heated up to a maximum temperature of $1600^{\circ} \mathrm{C}$ and held at this temperature for a period of 300 hours. The standard heating profile specified in each compact examination plan called for a controlled ramp of the furnace to $1600^{\circ} \mathrm{C}$ with soaks at 400 and $1250^{\circ} \mathrm{C}$, a hold at $1600^{\circ} \mathrm{C}$ for 300 hours, and then a controlled ramp back down to room temperature. The CCCTF performed as designed, except for a few interruptions while the furnace was being ramped up to $1600^{\circ} \mathrm{C}$. These interruptions were caused by several power supply problems and one mechanical problem with the cold finger. The root causes of these issues have been identified and addressed to ensure better reliability for future CCCTF operation.

Duri宸 the test period, condensable fission products (metals) were collected by the CCCTF in-furnace cold 善nger and gaseous fission products were collected from the helium sweep gas as it passed through liqui $\mathbf{m i t r o g e n - c o o l e d ~ c o l d ~ t r a p s . ~ D e p o s i t i o n ~ c u p s ~ a t t a c h e d ~ t o ~ t h e ~ i n - f u r n a c e ~ c o l d ~ f i n g e r ~ w e r e ~ p e r i o d i c a l l y ~}$ remof gar gerfor during the three-year irradiation test, as designed. No significant gaseous Kr-85 release was dete all ${ }^{2}$ esouter layers of the tristructural isotropic (TRISO) coating, and is the primary indicator for catâs tho particle failure during the heating test. However, some fission products were released from

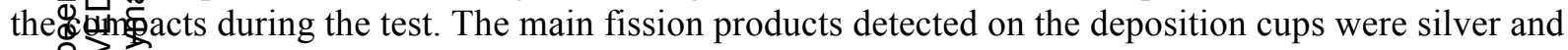
eurgim, with smaller amounts of strontium. Only trace amounts of cesium were released, except for Com far 3 - 3-2, where there was one particle with defective SiC that released virtually all its inventory of Cs 4 - 137 to the deposition cup. This was the only defective particle detected in the three contipscts क्tested, and post-test analysis determined the defect to be an as-fabricated SiC defect. The parfiscaiv not release $\mathrm{Kr}-85$, because one or more pyrocarbon layers remained intact.

응

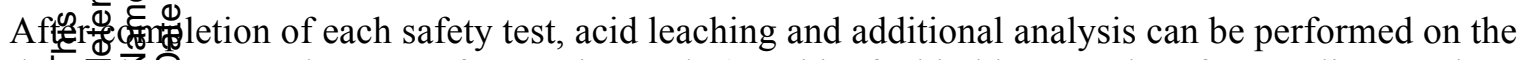

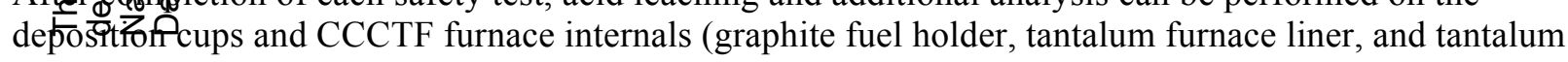
gas inlet line) to account for the entire inventory of fission products released from the compact. An average deposition cup collection efficiency for each detectable fission product can be calculated by determining the fraction of each fission product deposited on all the cups combined versus the total fission product release at the end of the test. This average collection efficiency can then be used to calibrate the time-dependent deposition cup data to estimate the total time-dependent fission product release from the compact.

Post-safety test analysis of the furnace internals from the Compact 3-3-2 and 3-2-2 furnace tests indicated deposition cup collection efficiencies close to $100 \%$ for silver and cesium, but only moderate efficiency for strontium, and a significantly limited efficiency for europium. Silver and cesium are both volatile at 
$1600^{\circ} \mathrm{C}$. This explains why almost all of what was released condensed on the cooled deposition cups, and very little remained in the graphite holder or tantalum components. Europium and strontium are probably released from the compact as carbides, and a large fraction of these elements remained in the graphite holder and tantalum can. This makes it difficult to determine collection efficiencies for these two elements with good accuracy or precision, so the uncertainty in the reported fission product releases for europium and strontium could be as high as a factor of two.

\section{Compact 3-3-2 Safety Test}

The Compact 3-3-2 safety test began on September 12, 2011, and experienced three interruptions at the beginning of the test. A power supply problem caused the circuit breaker to shut off power in response to an overcurrent condition during initial heat up. The test was restarted and the compact was heated to $1600^{\circ} \mathrm{C}$. After removal of the fourth deposition cup, the cold finger jammed and the furnace had to be shutdown until the problem could be corrected. As the compact was being reheated after the cold finger jam, the intermittent power supply failure reoccurred. The only other abnormality in the test was an air supply interruption late in the run, which resulted in the cold traps going off-line for a few hours. This did not impact the test because no $\mathrm{Kr}-85$ was released during that period. One interesting result of the inadvertent thermal cycling was that additional silver appeared to be released as a result. In order to better investigate this effect, two additional temperature cycles were intentionally added to the end of the run.

The overall time-dependent results of the Compact 3-3-2 furnace test are shown in Figure 1. The plotted fractional release values are the cumulative amount of each fission product collected on the deposition cups, adjusted for radioactive decay and average collection efficiency, and divided by the predicted compact inventory for each fission product at the end of the irradiation. The average collection efficiency was determined for each fission product using the combined analysis of all the deposition cups from the Compact 3-3-2 and 3-2-2 tests, both graphite holders, and the single Ta can used for the two sequential tests.

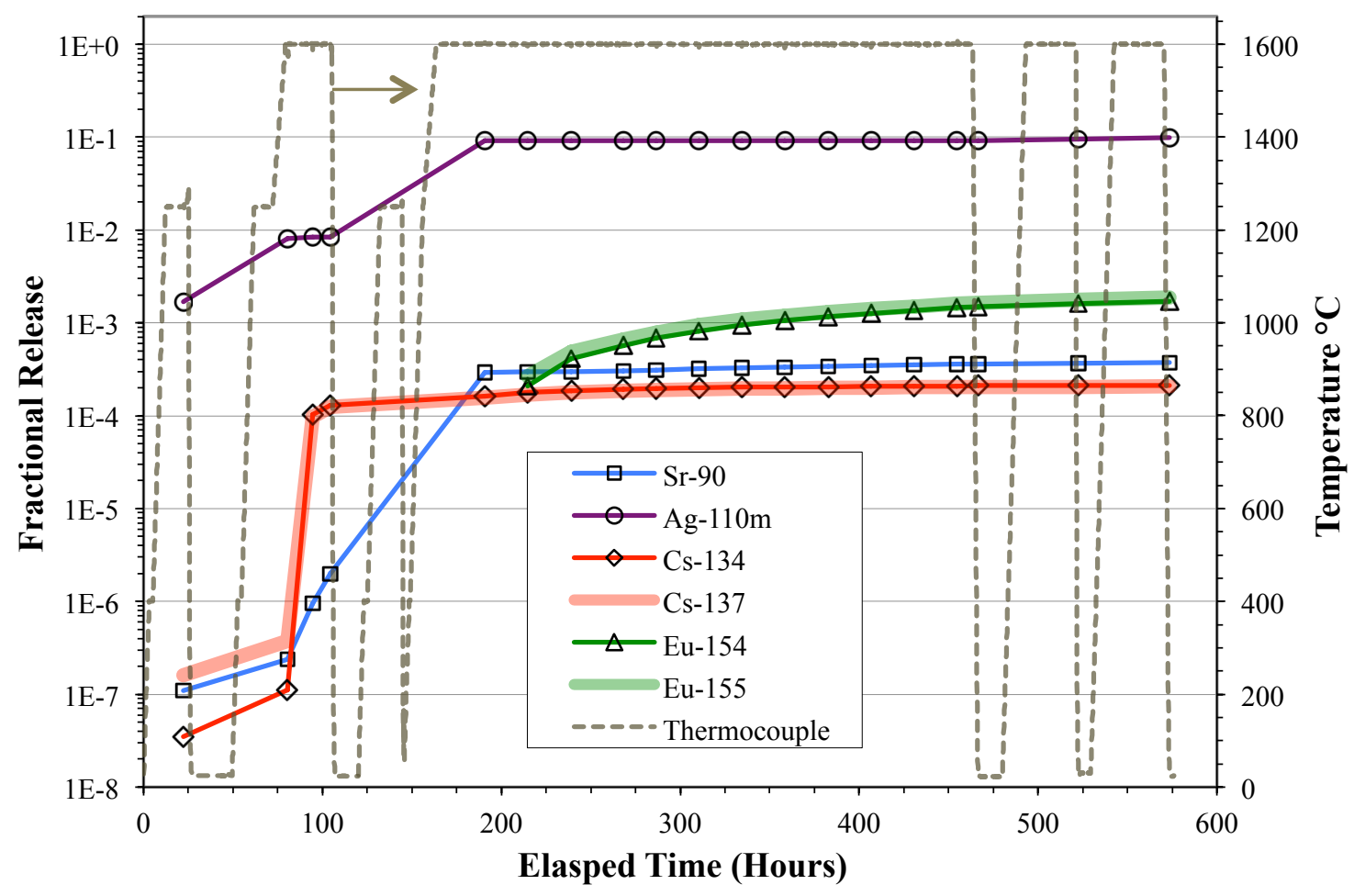

Figure 1. Release of fission products from Compact 3-3-2 during safety testing to $1600^{\circ} \mathrm{C}$. 
Table 1 lists the total releases for each detected fission product. The amount of cesium released from the compact was approximately equivalent to the cesium expected to be contained in a single particle. This is the only AGR-1 compact tested thus far that has released this much cesium. Cesium release during a safety test is typically related to a through-wall defect or failure of the $\mathrm{SiC}$ layer. After completion of the safety test, Compact 3-3-2 was electrolytically deconsolidated to recover the individual TRISO particles. Each particle was surveyed using the ORNL Irradiated Microsphere Gamma Analyzer (IMGA) to detect any particle with unusually low cesium content. One particle was identified with less than $40 \%$ of the expected cesium. This particle was imaged using x-ray tomography (Figure 2), and the SiC layer was determined to be porous. This type of defect occurs during fabrication when a particle is over-fluidized, causing it to pick up carbon soot on the surface of the IPyC prior to $\mathrm{SiC}$ deposition. The fact that no $\mathrm{Kr}-85$ was detected during the CCCTF test indicates that one or both of the pyrocarbon layers on this particle remained intact; no cracks in the pyrocarbon layers were evident in the x-ray imaging. The fact that negligible cesium was detected on the Capsule 3 components indicates that this abnormal particle did not release cesium during the irradiation test. This suggests that an open pathway through the $\mathrm{SiC}$ did not exist until the particle was heated to $1600^{\circ} \mathrm{C}$ during the post-irradiation safety test. It is likely that a thin outer layer of intact $\mathrm{SiC}$ was breached during the safety test.

Table 1. Cumulative fission product release from Compact 3-3-2 safety test

\begin{tabular}{|c|c|c|}
\hline Isotope & $\begin{array}{c}\text { Fraction of Calculated } \\
\text { Compact Inventory Released }\end{array}$ & $\begin{array}{c}\text { Equivalent Particle } \\
\text { Inventory }\end{array}$ \\
\hline${ }^{85} \mathrm{Kr}$ & $<1 \mathrm{E}-06$ & $<4 \mathrm{E}-03$ \\
\hline${ }^{90} \mathrm{Sr}$ & $3.71 \mathrm{E}-04$ & 1.5 \\
\hline${ }^{110 \mathrm{~m}} \mathrm{Ag}$ & $9.91 \mathrm{E}-02$ & 411 \\
\hline${ }^{134} \mathrm{Cs}$ & $2.12 \mathrm{E}-04$ & 0.88 \\
\hline${ }^{137} \mathrm{Cs}$ & $2.07 \mathrm{E}-04$ & 0.86 \\
\hline${ }^{154} \mathrm{Eu}$ & $1.72 \mathrm{E}-03$ & 7.1 \\
\hline${ }^{155} \mathrm{Eu}$ & $1.87 \mathrm{E}-03$ & 7.8 \\
\hline
\end{tabular}

Note: One particle is equivalent to a compact inventory fraction of $2.4 \times 10^{-4}$.

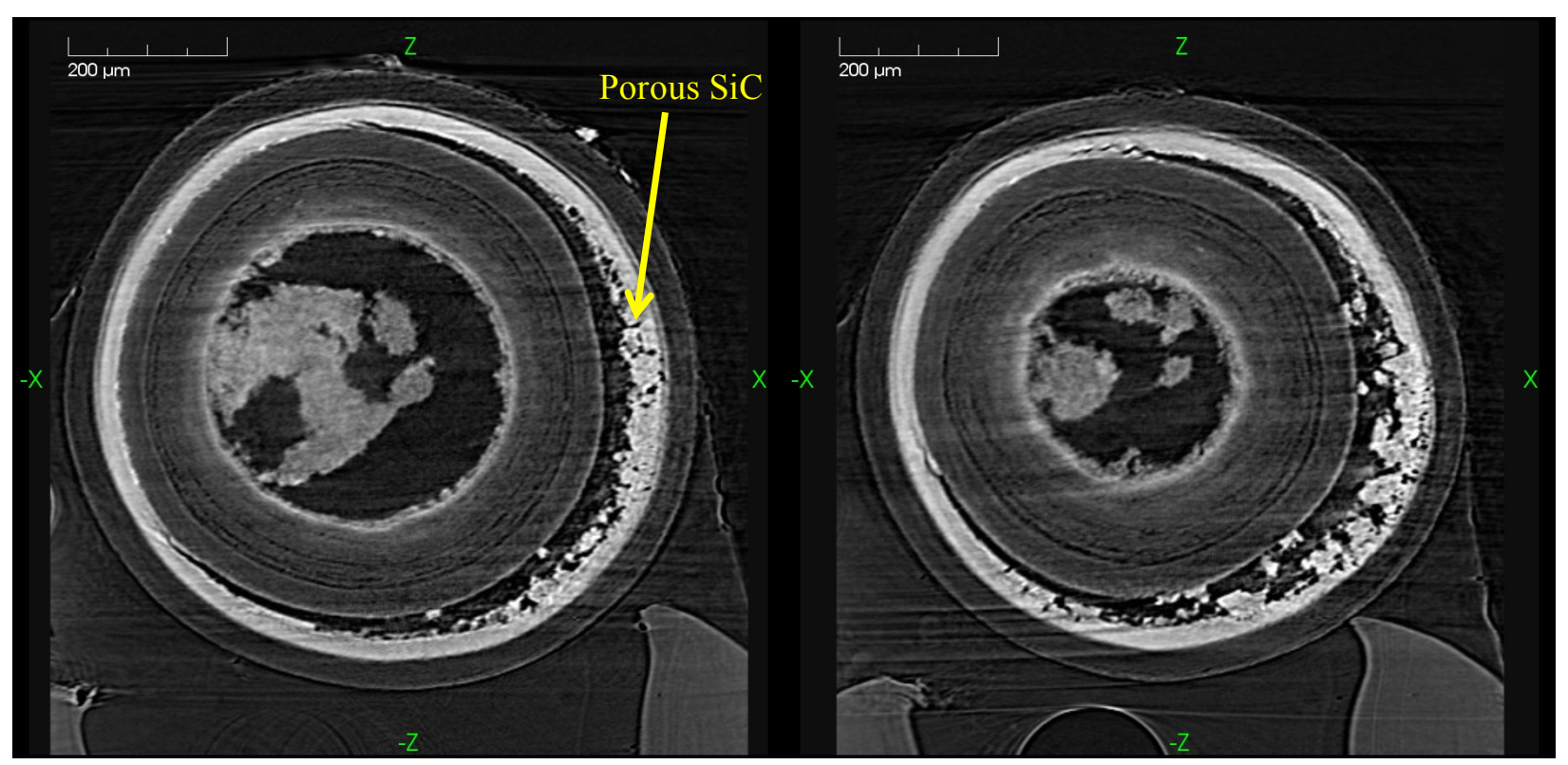

Figure 2. Two x-ray tomographs through parallel planes close to the center of the abnormal particle from AGR-1 Compact 3-3-2. 
Of particular note was that silver release was detected each time the compact was heated, but no significant silver release was detected while the compacts were held at elevated temperature in between the thermal cycles. As mentioned above, two additional thermal cycles were added to the end of the run to further investigate this effect. The silver data is presented using a linear scale in Figure 3 to make the multiple silver release events more evident. Silver release dropped off after the initial rise to $1600^{\circ} \mathrm{C}$. After the run was interrupted by the cold finger jam at around 100 hours into the test, the compact was heated to $1300^{\circ} \mathrm{C}$, cooled, then heated to $1600^{\circ} \mathrm{C}$. This resulted in a large spike in silver detected at the next deposition cup change. Constant exposure at $1600^{\circ} \mathrm{C}$ for almost 300 hours did not result in any additional significant silver collection. However, when the furnace was intentionally cooled and ramped back up to $1600^{\circ} \mathrm{C}$ two more times, more silver was released each time. At this point, it is not clear whether this unusual behavior is due to the temperature cycling or due to the local temperature gradients in the fuel and fuel holder driven by the changing temperature.

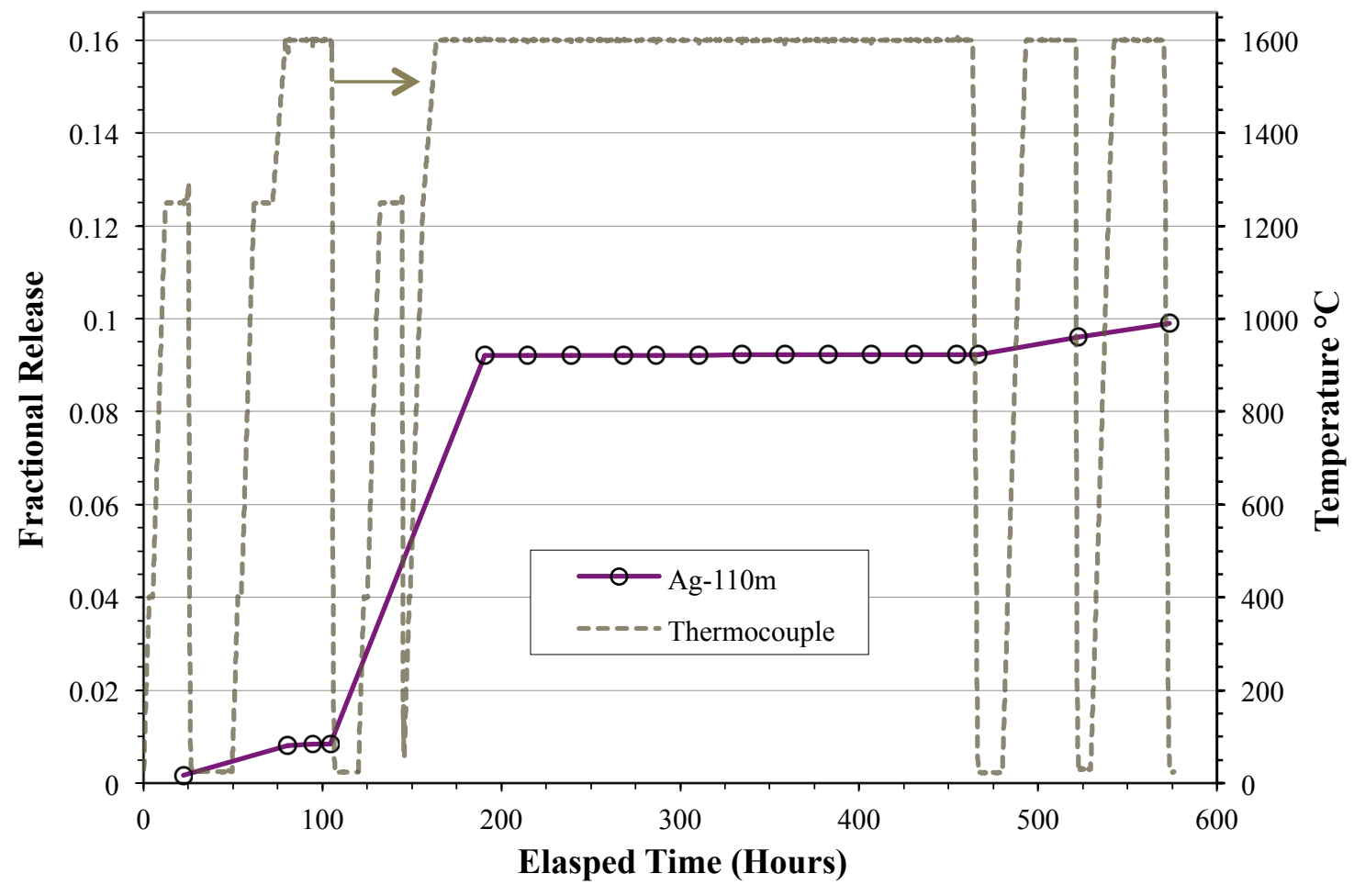

Figure 3. Silver release during AGR-1 Compact 3-3-2 heating test.

\section{Compact 3-2-2 Heating Test}

The safety test on Compact 3-2-2 began on November 2, 2011, and was interrupted by a power supply failure that occurred just as the compact reached $1600^{\circ} \mathrm{C}$. This resulted in the furnace temperature being cycled back down to room temperature before the furnace was restarted. As observed in the Compact 3-32 safety test, additional silver appeared to be released by the unplanned thermal cycling. The final heating profile and overall time-dependent results of the Compact 3-3-2 furnace test are shown in Figure 4. As for the Compact 3-3-2 data, the average deposition cup collection efficiency was determined for each fission product using the combined analysis of all the deposition cups from the Compact 3-3-2 and 3-2-2 tests, both graphite holders, and the single Ta can used for the two sequential tests. 


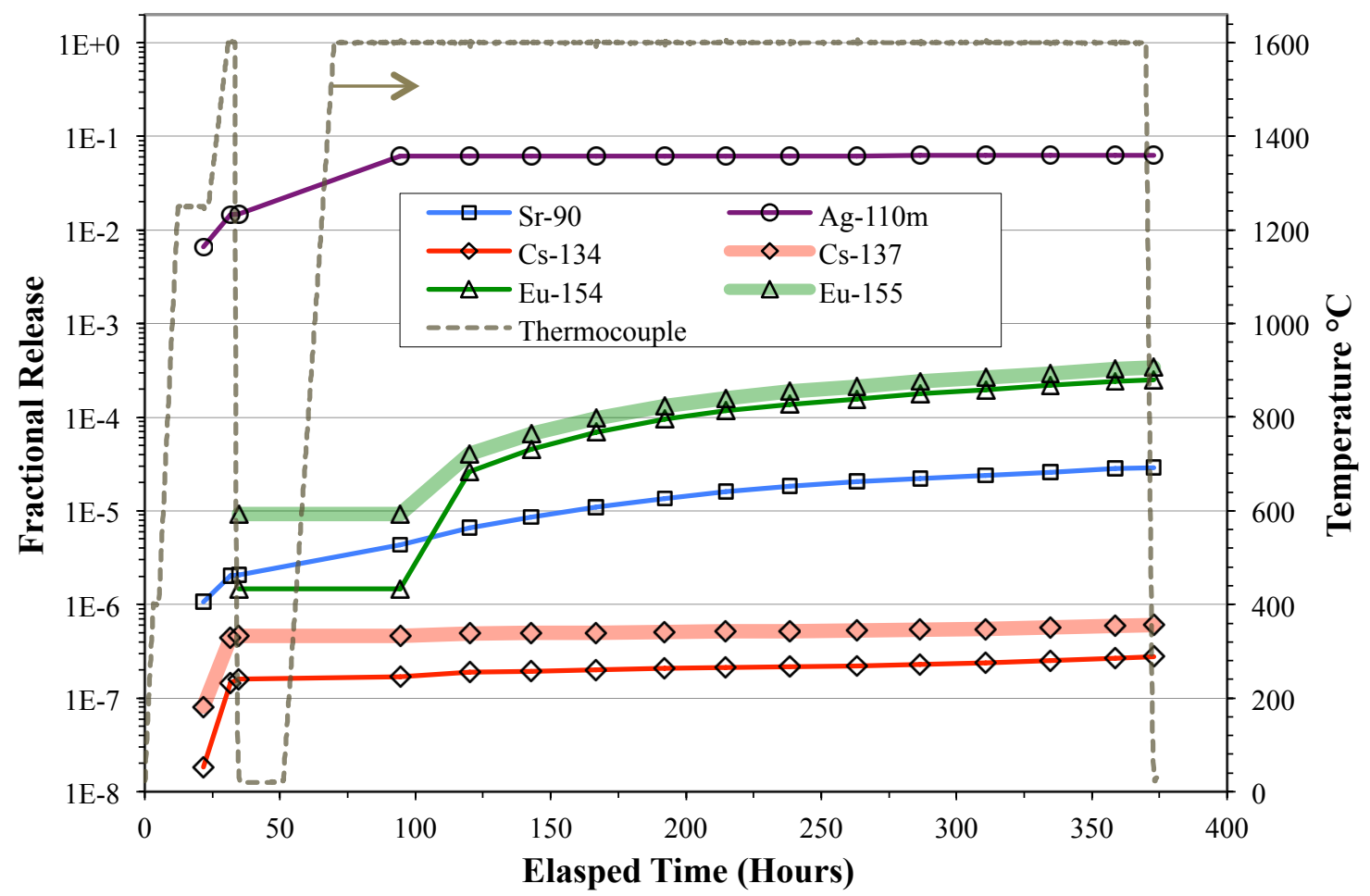

Figure 4. Release of fission products from Compact 3-2-2 during safety testing to $1600^{\circ} \mathrm{C}$.

Table 2 lists the total releases for each detected fission product. Cesium release was very low, indicating no particles with defective SiC. Leach-burn-leach (LBL) analysis performed after the safety test supported this conclusion. The fractional release values for the two cesium isotopes did not agree as well as they did for the results from Compact 3-3-2. This was because the measured quantities were low compared to the accuracy of the analysis.

Table 2. Cumulative fission product release from Compact 3-2-2 safety test

\begin{tabular}{|c|c|c|}
\hline Isotope & $\begin{array}{c}\text { Fraction of Calculated } \\
\text { Compact Inventory Released }\end{array}$ & $\begin{array}{c}\text { Equivalent Particle } \\
\text { Inventory }\end{array}$ \\
\hline${ }^{85} \mathrm{Kr}$ & $<1 \mathrm{E}-06$ & $<4 \mathrm{E}-03$ \\
\hline${ }^{90} \mathrm{Sr}$ & $2.91 \times 10^{-5}$ & 0.12 \\
\hline${ }^{110 \mathrm{~m}} \mathrm{Ag}$ & $6.23 \times 10^{-2}$ & 258 \\
\hline${ }^{134} \mathrm{Cs}$ & $2.75 \times 10^{-7}$ & $1.1 \mathrm{E}-3$ \\
\hline${ }^{137} \mathrm{Cs}$ & $5.97 \times 10^{-7}$ & $2.5 \mathrm{E}-3$ \\
\hline${ }^{154} \mathrm{Eu}$ & $2.51 \times 10^{-4}$ & 1.0 \\
\hline${ }^{155} \mathrm{Eu}$ & $3.38 \times 10^{-4}$ & 1.4 \\
\hline
\end{tabular}

Note: One particle is equivalent to a compact inventory fraction of $2.4 \times 10^{-4}$.

Europium and strontium release was lower than that from Compact 3-3-2. Fractional release of silver was relatively high compared to the other fission products, but lower than that observed for Compact 3-3-2. This could be due to the fact that Compact 3-2-2 was subjected to fewer thermal cycles. 


\section{Compact 6-2-1 Safety Test}

The Compact 6-2-1 safety test began on January 23, 2012, and went as planned with no power disruptions or equipment failures. Figure 5 shows the time-dependent fission product release. The average deposition cup collection efficiencies calculated for the Compact 3-3-2 and Compact 3-2-2 tests for silver (100\%) and cesium (97\%) were used to calculate the total fission product release for these two elements. Because most of the silver and cesium is collected on the cups, the uncertainty in these collection efficiencies is low $(<7 \%)$. The collection efficiencies used for europium and strontium were based on values previously used for the analysis of fission product release from the safety test on Compact 6-4-3, because of the greater uncertainty in the Compact 3-3-2 and Compact 3-2-2 values, which were based on the results of two sequential tests using the same tantalum furnace liner. However, the uncertainty in the europium and strontium collection efficiencies is still relatively high, because the measured values are low compared to the accuracy of the analysis. Additional post-safety test analysis of the furnace internals from the Compact 6-2-1 safety test will be performed to help further refine the europium and strontium collection efficiencies, but the uncertainty is expected to remain high compared to the more volatile fission products.

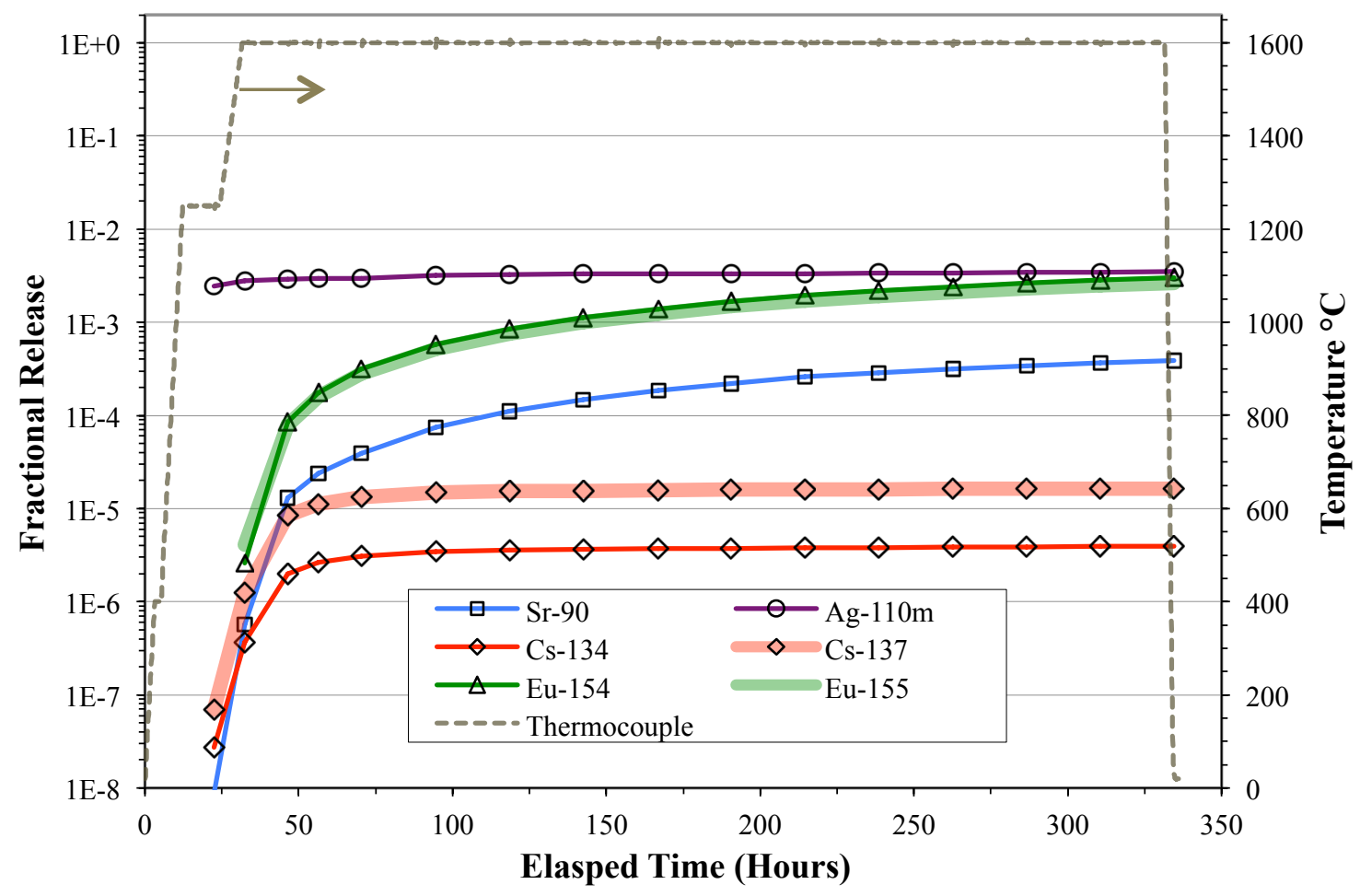

Figure 5. Release of fission products from Compact 6-2-1 during safety testing to $1600^{\circ} \mathrm{C}$.

Table 3 lists the total releases for each detected fission product. A trace amount of $\mathrm{Kr}-85$ was detected early in the run, and later quantified by off-line measurement of gases released from the sweep gas trap after the safety test was completed. The amount of $\mathrm{Kr}-85$ detected was near the limit of detection for the sweep gas trap system, and well below a level that would indicate TRISO-coating failure. Cesium release was again low, indicating no defective $\mathrm{SiC}$, and the difference in the reported values for the two cesium isotopes reflects the uncertainty in measuring these low release values. Europium and strontium release was similar to Compact 3-3-2. Silver release was considerably lower than observed for the two compacts from Capsule 3; a result that may be partially related to the absence of additional thermal cycling, but is also probably due to differences in the amount of silver available for release from the compacts. 
Table 3. Cumulative fission product release from Compact 6-2-1 safety test

\begin{tabular}{|c|c|c|}
\hline Isotope & $\begin{array}{c}\text { Fraction of Calculated } \\
\text { Compact Inventory Released }\end{array}$ & $\begin{array}{c}\text { Equivalent Particle } \\
\text { Inventory }\end{array}$ \\
\hline${ }^{85} \mathrm{Kr}$ & $4.63 \times 10^{-6}$ & 0.02 \\
\hline${ }^{90} \mathrm{Sr}$ & $3.89 \times 10^{-4}$ & 1.6 \\
\hline${ }^{110 \mathrm{~m}} \mathrm{Ag}$ & $3.51 \times 10^{-3}$ & 15 \\
\hline${ }^{134} \mathrm{Cs}$ & $3.93 \times 10^{-6}$ & 0.02 \\
\hline${ }^{137} \mathrm{Cs}$ & $1.65 \times 10^{-5}$ & 0.07 \\
\hline${ }^{154} \mathrm{Eu}$ & $3.03 \times 10^{-3}$ & 13 \\
\hline${ }^{155} \mathrm{Eu}$ & $2.66 \times 10^{-3}$ & 11 \\
\hline
\end{tabular}

Note: One particle is equivalent to a compact inventory fraction of $2.4 \times 10^{-4}$.

\section{Conclusion}

Overall, the CCCTF performed well except for the power supply overcurrent problem and cold finger insertion problem that have now been addressed. As originally designed, the cooled-deposition cups have a high efficiency for collection of silver and cesium, and the sweep gas trap system has a good sensitivity to release of $\mathrm{Kr}-85$. Time-dependent monitoring of europium and strontium (not originally part of the CCCTF design) is difficult due to the fact that these elements do not readily release from the graphite and tantalum furnace internals. Analysis of the CCCTF furnace internals at the end of each test will be required for accurate assessment of the total cumulative release of the elements. Very good agreement is being obtained between observations made during the safety tests and post-test PIE, such as analysis by LBL and IMGA. In addition, the ability to survey and extract individual particles with abnormally high fission product release has been demonstrated.

Cesium appears to be retained well at $1600^{\circ} \mathrm{C}$, except when particles have through-wall defects in the $\mathrm{SiC}$ layer. The lack of $\mathrm{Kr}-85$ release in the sweep gas and results of post-safety test LBL analyses, which show no exposed kernels, indicate that the TRISO coating is remaining intact when the compacts are heated to $1600^{\circ} \mathrm{C}$. Significant quantities of silver and europium were released from the compacts during the safety test. Silver appears to come out of the compact immediately upon heating, but then no further release occurs unless the temperature is cycled. Collection of europium on the deposition cups occurs over a longer time period. It is possible that the silver detected at the beginning of each run, and the europium and strontium collected on the deposition cups throughout the safety test, are coming from the compact matrix, as opposed to transport through intact $\mathrm{SiC}$ layers. Silver and europium are known to escape through intact $\mathrm{SiC}$ during irradiation, and the quantities being detected during the safety tests are in the range of what has been detected in the matrix of as-irradiated compacts. Further PIE of compacts before and after safety testing will help to further investigate this possibility.

The mechanism for silver release due to thermal cycling needs to be studied further and could be an important factor in silver release during irradiation. Particles are being sorted with the IMGA according to their silver content, which has been found to vary significantly within each compact. X-ray tomography and mechanical cross sectioning, followed by analysis with optical and scanning electron microscopes, may help determine why silver retention varies, but thermal history may also play a key role. Furnace testing of individual particles using various thermal profiles would help provide additional understanding of the effect of maximum temperature and temperature gradient on silver retention.

\section{Acknowledgment}

This work was supported by the U.S. Department of Energy, Office of Nuclear Energy, under the Very High Temperature Reactor Technology Development Office/Advanced Gas Reactor Fuel Development and Qualification Program. 